\title{
Novel interactions between ERa-36 and STAT3 mediate breast cancer cell migration
}

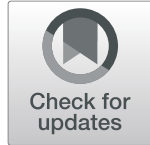

Yuan Xiang ${ }^{1 \dagger}$, Jia Peng Li ${ }^{1 \dagger}$, Wei Guo ${ }^{2}$, Dan-Qun Wang ${ }^{3}$, Ao Yao ${ }^{1}$, Hui-Min Zhang ${ }^{1}$, Feng Huang ${ }^{1}$, Han-Han Li ${ }^{1}$, Zhou-Tong Dai ${ }^{1}$, Zi-Jiang Zhang ${ }^{1}$, Hui Li ${ }^{1}$, Yao Tan ${ }^{4}$, Kun Chen ${ }^{5}$, Le-Yuan Bao ${ }^{1 *}$ and Xing-Hua Liao ${ }^{1,2^{*}}$ (D)

\begin{abstract}
Background: Breast cancer is the leading cause of cancer death in women worldwide which is closely related to metastasis. But the exact molecular mechanism of ERa-36 and STAT3 on metastasis is still not fully understood.

Methods: MCF-7 and MDA-MB-231 human breast cancer cell lines and MCF-10A were overexpressioned or knockdown ERa-36 and STAT3 and tested for migration, invasion and proliferation assays. Direct interaction of STAT3 and ERa-36 were analyzed by coimmunoprecipitation assays. The effect of STAT3 and ERa-36 on MMP2/9 expression was analyzed by qPCR and western blotting. STAT3 phospholyation and acetylation by ERa-36 and p300 were observed and quantified by coimmunoprecipitation assays and western blotting.

Results: Cross-talk between ERa-36 and STAT3 was demonstrated to mediate through a direct physical association between the two proteins. Furthermore, the interaction between ERa-36 and STAT3 was demonstrated to give rise to functional changes in their signaling events. Both MMP2 and MMP9 expression require the binding of the newly identified protein complex, ERa-36-STAT3, to its promoter, the second phase, which is more robust, depends on ERa-mediated recruitment of p300 onto the complex and the subsequent acetylation of STAT3. In addition, STAT3 is tyrosine-phosphorylated in a biphasic manner, and the late phase requires ERa-36-mediated p300-dependent acetylation. Furthermore, interference with acetylation of STAT3 by overexpression of acetylation null STAT3 mutant led to the loss of MMP2 and MMP9 expression. ChIP analysis and reporter gene assays revealed that ERa-36-STAT3 complex binding to the MMP2 and MMP9 promoter led to an enhanceosome formation and facilitated MMP2 and MMP9 expression.
\end{abstract}

Conclusions: Our studies demonstrate for the first time that the function of MMP2 and MMP9 in breast cancer cell migration, which is mediated by interactions between ERa-36 and STAT3.

Keywords: ERa-36, STAT3, Breast cancer, Migration

\section{Background}

Estrogen exerts most of its biological effects through the estrogen-specific transcription factor, the estrogen receptor (ER) [1]. The estrogen activated ERs form dimers and subsequently associate with specific consensus DNA sequences called estrogen response elements (ERE) located in the promoter regions of target genes to regulate gene transcription. ER is a member of the nuclear receptor super family and shares the common protein structure of this family $[2,3]$. The protein can be divided into

\footnotetext{
* Correspondence: Leyuan.bao@wust.edu.cn; xinghualiao@wust.edu.cn

†Yuan Xiang and Jia Peng Li contributed equally to this work.

${ }^{1}$ Institute of Biology and Medicine, Wuhan University of Science and

Technology, Wuhan, Hubei 430081, China

Full list of author information is available at the end of the article
}

several functional domains, denoted as A to $\mathrm{F}$ from the $\mathrm{N}$ terminus to the $\mathrm{C}$ terminus. The most conserved DNA-binding domain (DBD) $\mathrm{C}$ is comprised of two distinct zinc fingers and is responsible for DNA-binding and protein dimerization. The C-terminal $\mathrm{E}$ domain or ligand binding domain (LBD) plays important roles in mediating ligand binding, receptor dimerization, nuclear translocation, and ligand-dependent transactivation (AF2) of target gene expression. The N-terminal A/B domain is highly variable in both sequence and size. It usually contains a transactivation function (AF-1), which activates target genes by directly interacting with components of the core transcription machinery or with coactivators that mediate signaling to the downstream

(C) The Author(s). 2019 Open Access This article is distributed under the terms of the Creative Commons Attribution 4.0 International License (http://creativecommons.org/licenses/by/4.0/), which permits unrestricted use, distribution, and 
proteins. The hinge domain $\mathrm{D}$ contributes flexibility to the DBD versus LBD and has also, in some cases, been shown to influence the DNA-binding properties of individual receptors, thus serving as an anchor for certain co-repressor proteins. Finally, the C-terminal $\mathrm{F}$ domain has been shown to contribute to the transactivation capacity of the receptor [4]. But its other functions, if any, are to a large extent unknown.

$E R \alpha-36$ is generated from a promoter located in the first intron of the ER $\alpha-66$ gene and differs from the ER $\alpha-66$ by lacking both transcriptional activation domains (AF-1 and AF-2) but retaining the DNA-binding and dimerization domains, and partial ligand-binding domains $[5,6]$. ER $\alpha-36$ was reported to be a novel membrane associated ER that mediates rapid estrogen and anti-estrogen signaling in both ER-positive and -negative breast cancer cells predominantly expressed outside the cell nucleus and at the plasma membrane of both ERpositive and -negative breast cancer cells, mediates rapid estrogen and anti-estrogen signaling such as activation of the MAPK/ERK and PI3K/AKT signaling pathways and stimulation of cell proliferation [6, 7].

STATs are a family of transcription factors that consist of seven members. They contain a dimerization domain, a coiled-coil domain, a DNA-binding domain, a src homology 2 domain, and a conserved single tyrosine residue whose phosphorylation is required for its activation in the $\mathrm{N}$-terminal region, whereas a transcriptional activation domain is present in the $\mathrm{C}$-terminal region [8]. Interestingly, the STATs are the only characterized transcription factors thus far that are activated by tyrosine phosphorylation, and this post-translational modification inessential for their Src homology 2-mediated homo- or heterodimer formation $[9,10]$.

Our previous and other studies have shown that STAT3 promoted breast cancer cell migration, and MRTF-A and STAT3 synergistically increased MDAMB-231 cell migration by promoting the expression of migration markers Myl-9, Cyr-61, urokinase-type plasminogen activator (uPA) and osteopontin (OPN) and inhibiting the expression of breast cancer metastasis suppressor 1 (BRMS1, [11, 12]). And MiR-93-5p inhibited the EMT of breast cancer cells via targeting MKL-1 and STAT3 [13]. Thus, it is interesting to note that although both ER $\alpha-36$ and STAT3 belong to two different groups of transcription factors and are activated by opposite post-translational modifications; both target the two genes, MMP2 and MMP9, in mediating cell proliferation and migration [14-16].

It has been reported that MMP2 and MMP9 were closely related to cells migration in various cancers including bladder cancer, osteosarcoma, hepatocellular carcinoma, thyroid cancer, gastric adenocarcinoma [1720], which are mediated by many signal pathways including MAPK/P38 signaling [21, 22], PI3K/AKT signaling [23, 24], Wnt/Frizzled signaling [25] accompanied by epithelial to mesenchymal transition (EMT), drug resistance $[26,27]$ and tumor progression. Because MMP2 and MMP9 play a critical role in cell cycle progression, it is not surprising that cells employ multiple mechanisms in its regulation in response to a plethora of stimuli $[16,28]$. However, what is not known is whether there is any cross-talk among the multiple transcription factors that are activated by various signaling mechanisms in the induction of MMP2 and MMP9 expression in mediating cell cycle progression and cell migration in response to an agonist. Toward this end, we report here for the first time that ER $\alpha-36$ and STAT3, members of two different families of transcription factors, exist as a heterodimer in quiescent cells and in response to thrombin bind to the MMP2 and MMP9 promoter in a cooperative and biphasic manner. In addition, ER $\alpha-36$ facilitates STAT3 acetylation via recruiting p300 association. In response to IL-6, STAT3 is tyrosine-phosphorylated in a biphasic manner in which the late phase phosphorylation requires ER $\alpha$-36-dependent p300-mediated acetylation. Furthermore, the cooperative interaction between these two transcription factors lead to a biphasic expression of MMP2 and MMP9, with the first phase influencing cell migration.

\section{Materials and methods Reagents}

Recombinant human interleukin 6(IL-6), AG490, estradiol (E2) and tamoxifen (TAM) protein were obtained from R\&D Systems and Sigma. Antibodies against MMP2, MMP9, p300, ER $\alpha-36$, and STAT3 were purchased from Cell Signaling and Abcam; Myc, Flag and HA antibody were purchased from proteintech.

\section{Cell lines}

MCF-7 and MDA-MB-231 human breast cancer cell lines and MCF-10A were grown in Dulbecco's modified Eagle's medium (DMEM)(GIBCO) supplemented with $10 \%$ fetal bovine serum at $37^{\circ} \mathrm{C}$ in a $5 \% \mathrm{CO}_{2}$ incubator.

\section{Plasmids}

The pCDNA3.1-ER $\alpha-36-$ Myc contained a cDNA encoding amino acids 1-311 of human ER $\alpha-36$, the pCDNA3.1-STAT3-Flag contained a cDNA amino acids 1-769 of human STAT3. The vector pCDNA3.1 was purchased from Promega. The promoter regions of MMP2 $(-904 /+50)$ and MMP9 $(-4136 /+18)$ were amplified by PCR and then were cloned into pGL3 luciferase reporter vector, respectively. The primers used to create MMP2-luc and MMP9-luc was as follow: MMP2: 5' - GTCAGCTAGCAGAGACGGTTGTCACAGGGA - 3'(sense) and 5' - AGACCTCGAGTGCTACTCCTGG 
CCTCTACG - 3'(antisense); MMP9: 5' - GTCAGCTA GCGCTTCCTTACTGACGGTGCT - 3'(sense), and 5' AGACCTCGAGGGTGAGGGCAGAGGTGTC 3'(antisense); the vector pGL3(Pomega) was used as a control. Additional luciferase reporter constructs of MMP2 and MMP9 promoter containing mutations to putative GAS were generated using the QuickChange site-directed mutagenesis kit (Stratagene, La Jolla, CA). The MMP2-WT-luc GAS was mutated from -TTCGTG GAA - to -TAGACGTAA -(MMP2-M-GAS-luc) and these nucleotide mutations abolished STAT3-binding sites. The primers used were as follows: MMP2-M-GASluc: forward 5': GGGGAATAGACGTAACTGAGGGCT CCTCCCCTTTTTAGACCATATA $3^{\prime}$; reverse 5': CCTCAGTTACGTCTATTCCCCACTCACTCTTGAA

TCCTTTCCTGCG 3'. The MMP9-WT-luc GAS was mutated from - TTCCCCTGAA - to - TAGATCGTAA (MMP9-M-GAS-luc) and this nucleotide mutations abolished STAT3-binding sites. The primers used were as follows: MMP9-M-GAS-luc: forward 5': TTGCCATA GATCGTAAGCTAGGGATGGCAGGTGTGTTTGT GGGTTG 3'; reverse 5': CCTAGCTTACGATCTATG GCAATTCCCACACTGACTCTTAGAGTCC 3'.

\section{Wound-healing assays}

For wound healing assays, cells were seeded on 6-well dishes. Twenty-four hours after transfection, wounding was induced by scratching the monolayer with a micropipette tip and the dish was placed at $37^{\circ} \mathrm{C}$ in a $5 \% \mathrm{CO}_{2}$ incubator chamber. Pictures were acquired after $0 \mathrm{~h}$ and $24 \mathrm{~h}$ (in the case of MDA-MB-231) or $36 \mathrm{~h}$ (in the case of MCF-7) using a microscope.

\section{Transwell migration assays}

Cell migration was tested in $8-\mu \mathrm{m}$-pore polycarbonate membrane Transwell chambers (Corning) essentially as described previously $[12,13,29,30]$. Cells were resuspended in DMEM/F12 without FBS (fetal bovine serum), and 75,000 cells were added to the top chamber of the Transwell chambers. DMEM/F12 containing 10\%FBS was added to the bottom chamber, and cells were allowed to migrate for $24 \mathrm{~h}$. Non-migrated cells were scraped off the top of the membrane. Migrated cells were fixed in $4 \%$ formaldehyde and stained in Giemsa. Cells were counted under a microscope in five different fields in duplicate wells, in at least three independent experiments.

Reverse-transcription polymerase chain reaction (RT-PCR) and quantitative real-time RT-PCR (qRT-PCR)

RT-PCR and qRT-PCR analysis were carried out as described previously $[29,30]$. Briefly, total cellular RNA was extracted from cultured cells with Trizol reagent (Invitrogen) and $2 \mu \mathrm{g}$ of total RNA was reverse- transcribed using M-MLV reverse transcriptase (Promega) according to the manufacturer's instructions. The thermal cycle profile was as follows: denaturation for 30 $\mathrm{s}$ at $95^{\circ} \mathrm{C}$, annealing for $45 \mathrm{~s}$ at $52-58^{\circ} \mathrm{C}$ depending on the primers used, and extension for $45 \mathrm{~s}$ at $72{ }^{\circ} \mathrm{C}$. Each PCR reaction was carried out for $28-32$ cycles. PCR products were visualized on $2 \%$ agarose gels stained with ethidium bromide (EB) under UV trans-illumination. qRT-PCR was performed in an Applied Biosystems StepOne $^{\text {tm }}$ Real-Time PCR System. Fast SYBR ${ }^{\circ}$ Green Master Mix was obtained from Applied Biosystems. Data were shown as relative expression level after being normalized by Glyceral-dehyde-3-phosphate dehydrogenase (GAPDH). The PCR primer sequences are as follows, GAPDH: F-5'ATTCAACGGCACAGTCAAGG3', R5'GCAGAAGGGGCGGAGATGA3'; MMP2:F-5' CCCA CTGCGGTTTTCTCGAAT 3', R-5' CAAAGGGGTA TCCATCGCCAT 3';MMP9:F-5' AGACCTGGGCAG ATTCCAAAC 3', R-5' CGGCAAGTCTTCCGAGTA GT 3';STAT3:F-5'CAGCGAGAGCAGCAAAGAAG3', R-5'GGAATGTCGGGGTAGAGGTAG3'.

\section{Western blotting}

Western Blotting was performed as described previously $[11,30]$. The total proteins of treated and tranfected cells were immunoblotted with rabbit p300, ER $\alpha-36$ (Abcam), mouse phosphorylated STAT3 (Abcam), rabbit STAT3 (Abcam), rabbit MMP2(Abcam), mouse MMP9 (Abcam) and mouse p53, $\beta$-tubulin, and GAPDH (Santa Cruz) antibodies overnight at $4{ }^{\circ} \mathrm{C}$, and then incubated with IR Dye ${ }^{\mathrm{mi}}-800$ conjugated anti-rabbit secondary antibodies and IR Dye $\mathrm{ex}^{\mathrm{mx}}-680$ conjugated anti-mouse secondary antibodies (Li-COR) for $30 \mathrm{~min}$ at room temperature (RT). The specific proteins were visualized by Odyssey ${ }^{\mathrm{mm}}$ Infrared Imaging System (Gene Company). GAPDH expression was used as an internal control to show equal loading of the protein samples.

\section{Immunofluoresence staining}

Immunocytochemistry assays were performed as described previously $[11,31]$. The cells after treatment were fixed in $4 \%$ paraformaldehyde for $15 \mathrm{~min}$, and then blocked with normal goat serum for $20 \mathrm{~min}$. Then, rabbit MMP2(1:200 dilution, Abcam), and mouse MMP9(1:200 dilution, Abcam) antibodies were added and incubated in a humid chamber over night. After washing with PBS twice, cells were incubated with appropriate secondary antibodies (fluorescein isothiocyanate (FITC)-goat anti-rabbit or anti-mouse IgG, SantaCruz) for $30 \mathrm{~min}$ at $37^{\circ} \mathrm{C}$. After washing with PBS, the samples were observed under laser scanning confocal microscope (Olympus). 4',6-diamidino-2-phenylindole (DAPI) stain (blue) highlights the total nuclei. 


\section{Luciferase reporter assays}

Luciferase assays were performed as described previously $[12,31] .24 \mathrm{~h}$ after transfection, luciferase activity was measured by on a Synergy ${ }^{\text {ma }} 4$ (Bioteck). Transfection efficiencies were normalized by total protein concentrations of each luciferase assay preparations. All experiments were performed at least three times with different preparations of plasmids and primary cells, producing qualitatively similar results. Data in each experiment are presented as the mean \pm standard deviation of triplicates from a representative experiment.

\section{Chromatin immunoprecipitation (ChIP) assay}

ChIP analysis was performed using a commercially available kit (Enzymatic Chromatin IP (Magnetic Beads), Cell Signaling Technology). MDA-MB-231 cells were transfected with STAT3 and ER $\alpha-36 /$ STAT3 for $24 \mathrm{~h}$. Proteins bound to DNA were cross-linked using formaldehyde at a final concentration of $1 \%$ for $20 \mathrm{~min}$ at room temperature. Protein-DNA complexes were immunoprecipitated using primary antibodies for ER $\alpha$-36 (Abcam). STAT3 and MMP2 promoter complexes and STAT3 and MMP9 promoter complexes were measured by PCR. The primers used for the amplification of the human MMP2 promoter was: MMP2-GAS-box: forward-5' AGACGGTTGTCA CAGGGAG 3', and reverse-5' ATGGCAATGTGGGG AGGT $3{ }^{\prime}$. And the primers used for the amplification of the human MMP9 promoter was: MMP9-GAS-box: forward-5' TGACTTGGTGTTAATAGGGACT 3 ', and reverse-5' GGCAGGATGTGGAGGAGA $3{ }^{\prime}$. The samples were electrophoresed using a $2 \%$ agarose gel, and visualized by ethidium bromide staining.

\section{Coimmunoprecipitation}

Plasmid expressing Myc-ER $\alpha-36$ and Flag-STAT3 were cotransfected into MDA-MB-231 cells. Lysates were collected $48 \mathrm{~h}$ posttransfection, and Myc antibody (Protein tech) was used to precipitate Myc-ER $\alpha-36$ or Flag antibody (Protein tech) was used to precipitate Flag-STAT3, respectively. The resulting mixture was washed, subjected to sodium dodecyl sulfate-polyacrylamide gel electrophoresis (SDS-PAGE), transferred to a NC membrane (Pall), first revealed by Myc antibody (Protein tech) to visualize Myc epitoped ER $\alpha-36$ or Flag antibody (Protein tech) to detect Flag epitoped STAT3, and then reprobed with Flag antibody (Protein tech) to detect Flag epitoped STAT3 or reprobed with Myc antibody (Protein tech) to detect Myc epitoped ER $\alpha-36$, respectively.

\section{Statistical analysis}

Statistical analyses were conducted using Statistical Program for Social Science (SPSS) software 17.0 (SPSS, USA). Percentages and ratios were arcsine transformed prior to data analysis. A 2 -sided $P$ value of 0.05 was considered statistically significant. Comparisons between 2 groups were analyzed by Student's t-test. Data are presented as mean \pm SD unless otherwise stated.

\section{Results \\ IL-6 induces stat3 phosphorylation and mediates breast cancer cell migration through regulating MMP2/9 expression}

Toward understanding the mechanisms of breast cancer progression, we have previously reported that STAT3 promotes breast cancer cell migration by regulating Cyr61 and Myl9 expression [11]. Interleukin (IL)-6 drives many of the cancer 'hallmarks' through downstream activation of the Janus kinase/signal transducer and activator of transcription 3 (JAK/STAT3) signaling pathway [32], we wanted to find whether STAT3 plays a role in IL-6-induced MMP2 and MMP9 expression. IL-6 induced the expression of MMP2 and MMP9 in a biphasic manner at mRNA and protein levels (Fig. 1a, b, e and f) and the phospholyation STAT3(Fig. 1c and d). Based on these observations, we next examined the role of MMP2 and MMP9 in IL-6-induced breast cancer cell migration. Down-regulation of MMP2 expression by siRNA inhibited IL-6-induced breast cancer cell migration about 38\%(Fig. 1g) and Si-MMP9 inhibited IL-6induced breast cancer cell migration about 39\%(Fig. G), while Down-regulation of both MMP2 and MMP9 expression by siRNA inhibited IL-6-induced breast cancer cell migration about $20 \%$ (Fig. G).

\section{STAT3 mediates IL-6-induced MMP2 and MMP9 expression and breast cancer cell migration}

To test the role of STAT3 in IL-6 induced MMP2 and MMP9 expression, we overexpress STAT3 transfecting the cells with plasmid pCDNA3.1-STAT3, over-expression STAT3 significantly induced IL-6-induced MMP2 and MMP9 expression (Fig. 2a). To further verify the role of STAT3 in IL-6-induced MMP2 and MMP9 expression, we transfect the cells with specific STAT3 siRNA, results showed that depletion of STAT3 levels by siRNA suppressed IL-6 induced MMP2 and MMP9 expression (Fig. 2b). These results indicate that STAT3 mediates IL-6-induced MMP2 and MMP9 expression. To understand the role of STAT3 in IL-6-induced breast cancer cell migration, MDA-MB-231 cells that were transduced with either Ad-GFP or Ad-GFP-STAT3, the cells were then treated with and without IL-6, cell migration was measured by a modified Boyden chamber method. Results showed that overexpression of STAT3 enhanced MDA-MB-231 cell migration about $50 \%$ (Fig. 2c). In addition, depletion of STAT3 levels by its siRNA also blocked IL-6 induced MDA-MB-231 cell migration about 60\% (Fig. 2d). These observations indicate that IL-6-induced MDA-MB-231 cell migration and proliferation require STAT3-mediated MMP2 and MMP9 expression. 


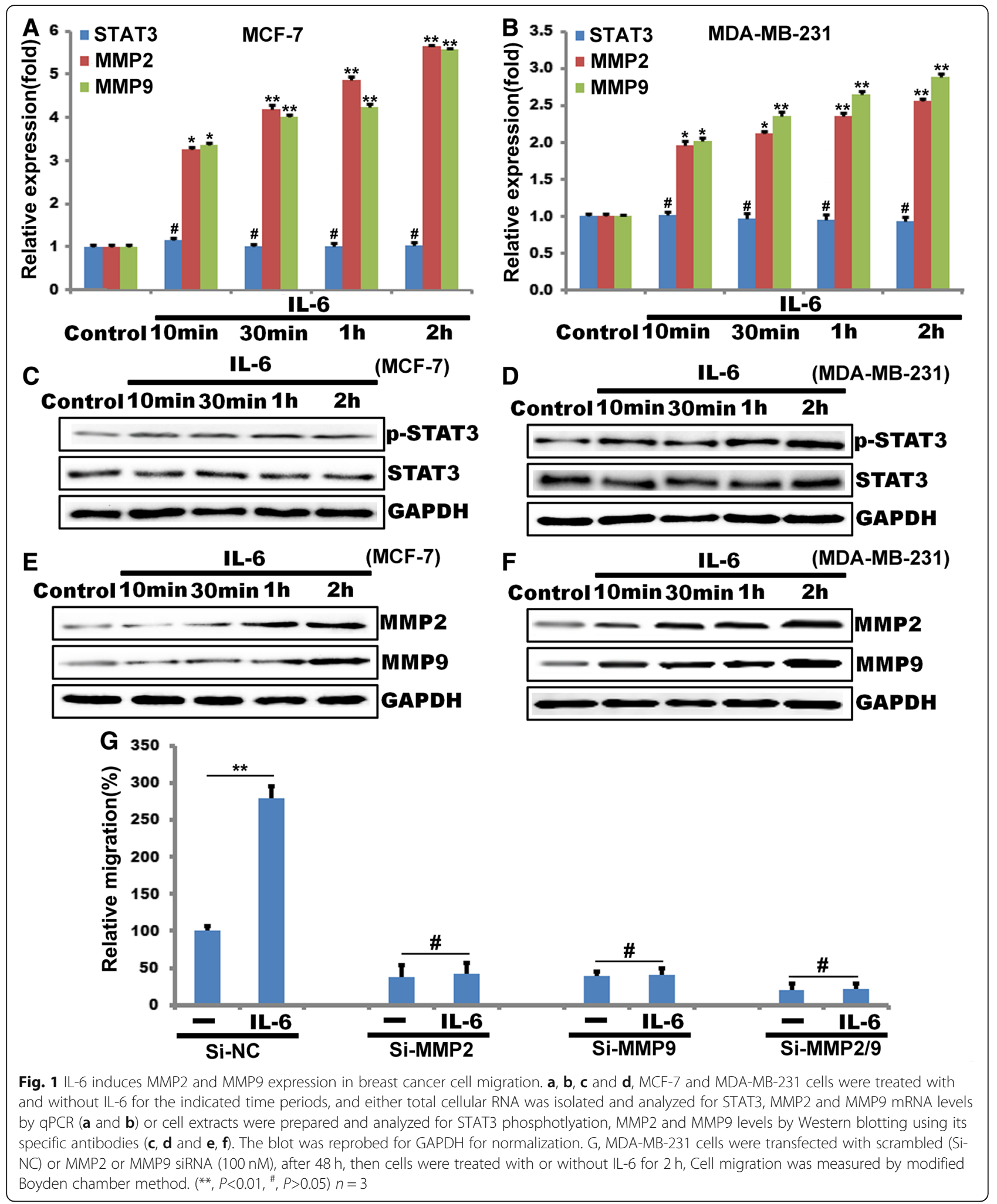

ERa-36 and STAT3 mediate IL-6-induced MMP2 and MMP9 promoter activity

Studies from our laboratory as well as others have shown that MMP2 and MMP9 expression is regulated at both transcriptional and post-transcriptional levels [14, 15]. To show STAT3 regulates IL-6-induced MMP2 and MMP9 expression, we first cloned $804 \mathrm{bp} \mathrm{MMP2} \mathrm{and}$ 4136 bp MMP9 promoter and analyzed the sequence for 

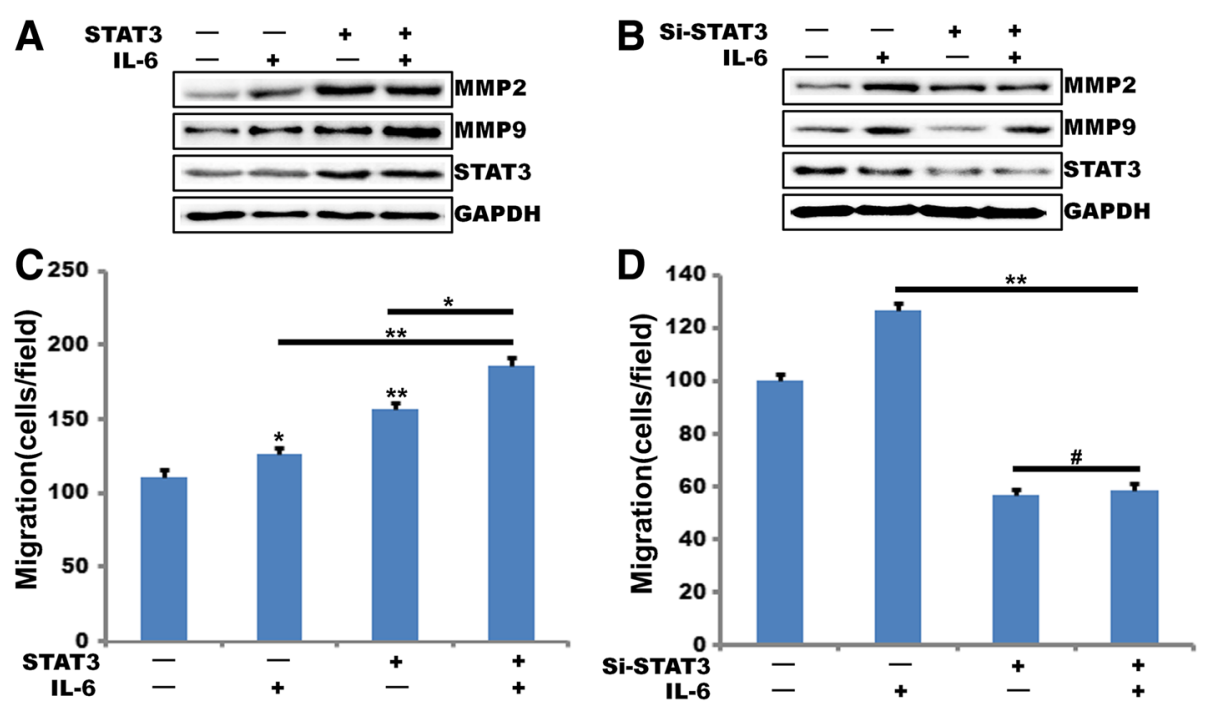

Fig. 2 STAT3 mediates IL-6 induced MMP2 and MMP9 expression and breast cancer cell migration. $\mathbf{a}$ and $\mathbf{b}$, MDA-MB-231 cells were either transduced with Ad-GFP or Ad-GFP-STAT3(a) or transfected with scrambled (Scr) or STAT3 siRNA (100 nM) (b), After 48 h, cells were treated with or without IL- 6 for $2 \mathrm{~h}$, and cell extracts were prepared. And analyzed by Western blotting for MMP2 and MMP9 levels using its specific antibodies. The blot was re-probed with anti-GAPDH antibodies for normalization. $\mathbf{c}$ and $\mathbf{d}$, all the conditions were the same as in $\mathbf{a}$ or $\mathbf{b}$ except that quiescent MDA-MB-231 cells were subjected to IL-6-induced migration assay (C and D). $\left({ }^{* *}, P<0.01,{ }^{\#}, P>0.05\right) n=3$

transcription factors binding elements using TRANSFAC $[33,34]$. We identified one putative STAT-binding element (GAS) in the MMP2 and MMP9 promoter region (Fig. 3a). To find whether IL-6 induces MMP2 and MMP9 promoter activity, MDA-MB-231 cells were transfected with full or truncated MMP2 and MMP9 promoter-luciferase constructs. Cells were either untreated or treated with IL-6 for $1 \mathrm{~h}$. Cell extracts were prepared and analyzed for luciferase activity. Compared with control, IL-6 induced a 2.5 -fold or 3-fold increase in luciferase activity with a full-length pGL3-MMP2-luc and pGL3-MMP9-luc construct, and deletion of sequences from in the promoter region resulted in the loss of a response to IL-6, indicating the presence of the IL-6-responsive elements in this region (Fig. $3 \mathrm{~b}$ and c). To understand the role of STAT3 and ER $\alpha-36$ in the regulation of MMP2 and MMP9 promoter activity, breast cancer cells were co-transfected with plasmids expressing STAT3 and ER $\alpha$-36 together with pGL3-MMP2-luc and pGL3-MMP9luc constructs. Luciferase activity was measured. Our results showed that STAT3 increased the luciferase activity by about 5.5 -fold in scrambled siRNA-transfected control cells, and this increase was enhanced by either overexpress $\mathrm{ER} \alpha-36$ or STAT3, indicating a role for ER $\alpha$ in STAT3-induced MMP2 and MMP9 promoter activity (Fig. 3d and e). Similarly, ER $\alpha-36$ enhances STAT3-induced MMP2 and MMP9 mRNA and protein level by real time PCR and Western blotting approaches (Fig. 3f, g and h).

\section{Direct interaction of STAT3 and ERa-36}

We next investigated whether ER $\alpha-36$ and STAT3 proteins interact by coimmunoprecipitation assays with
ER $\alpha-36$ and STAT3 overexpressed MDA-MB-231 cells. As shown in Fig. $4 \mathrm{~b}$ and d, ER $\alpha-36$ specifically interacted with STAT3. The domains of ER $\alpha-36$ and STAT3 that mediate their interaction were mapped by coimmunoprecipitation assays with a series of ER $\alpha-36$ and STAT3 deletion mutant proteins (Fig. 4c and d). With a series of STAT3 deletion mutant proteins, we found that mutant proteins lacking sequences $\mathrm{C}$-terminal region of STAT3 lose the ability to interact with ER $\alpha-36$ (Fig. 4a and b). Similarly, with a series of ER $\alpha-36$ deletion mutant proteins, we found that mutant proteins lacking sequences C-terminal region of ER $\alpha-36$ lose the ability to interact with STAT3 (Fig. 4c and d).

\section{ERa-36 associates with STAT3 and influences STAT3 phospholyation and acetylation}

It was well established that STAT3 is activated by phosphorylation at Tyr-705 [35, 36], and its DNA binding as well as transcriptional transactivation activity are enhanced by acetylation at Lys-685 [37]. Hence, we tested whether ER $\alpha$-36 interaction with STAT3 has any influence on STAT3 phosphorylation or acetylation. Surprisingly, ER $\alpha$-associated STAT3 was phosphorylated and acetylated with peak effects between 1 and $2 \mathrm{~h}$ of IL-6 treatment (Fig. 5a). To find whether there is any connection between STAT3 phosphorylation and its acetylation, first we determined the time course effect of IL-6 on STAT3 phosphorylation (Tyr-705) and acetylation (Lys685). However, STAT3 is acetylated in a delayed manner peaking between 1 and $2 \mathrm{~h}$ of IL- 6 treatment (Fig. $5 \mathrm{~b}$ ). Next, we tested the role of ER $\alpha-36$ on STAT3 

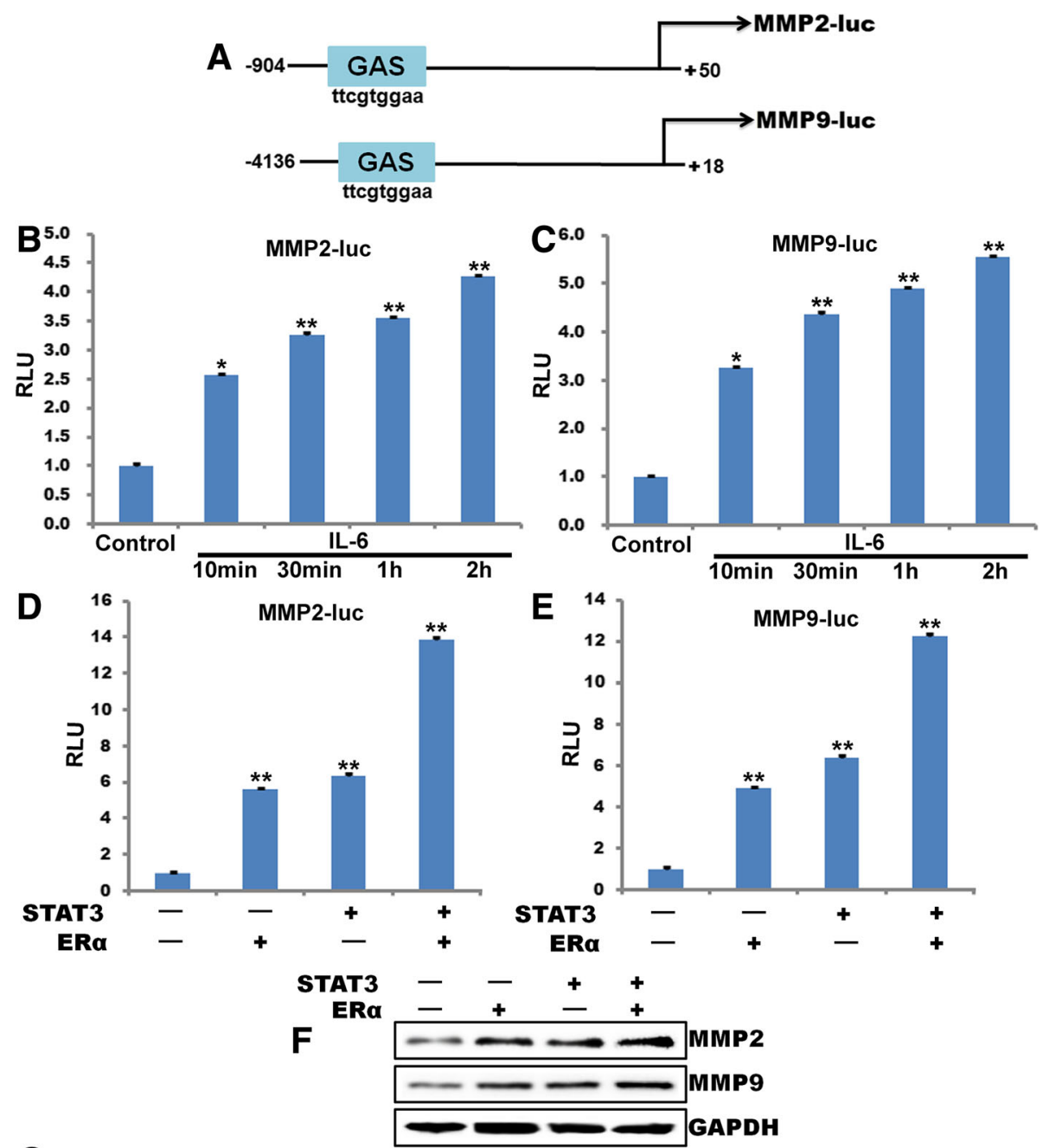

G

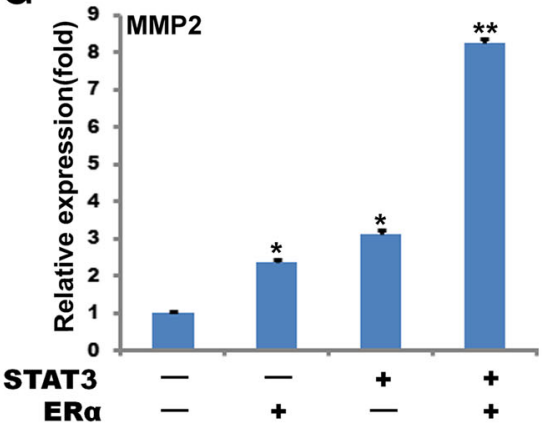

H

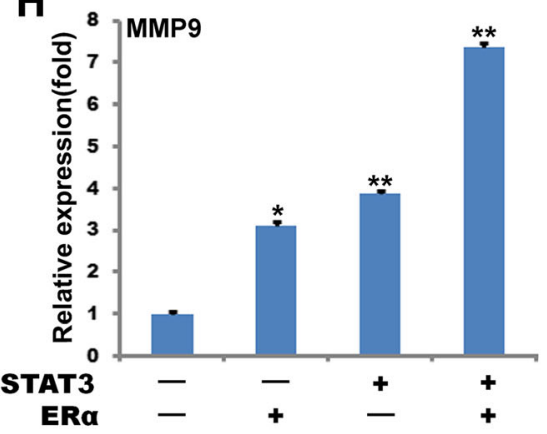

Fig. 3 ERa and STAT3 mediates IL-6 induced MMP2 and MMP9 promoter activity a, Schematic of the -904 MMP2 promoter and - 4136 MMP9 promoter, containing GAS element was used for luciferase reporter assay. $\mathbf{b}$ and $\mathbf{c}$, After MDA-MB-231 cells were treated with IL-6 for the indicated time periods. Then the luciferase reporter assays was used to test the transcriptional activity of MMP2 (b) and MMP9 (c). d and e, After MDA-MB-231 cells were transfected with ERa-36 or STAT3 for $24 \mathrm{~h}$. Then the luciferase reporter assays was used to test the tanscriptional activity of MMP2 (d) and MMP9 (e). f, $24 \mathrm{~h}$ post-transfected with ERa-36 or STAT3, total proteins were extracted and the protein level of MMP2 and MMP9 were detected by Western blotting analysis. GAPDH was used as a loading control. $\mathbf{g}$ and $\mathbf{h}$, MDA-MB-231 cells were transfected with ERa36 or STAT3 for $24 \mathrm{~h}$, total RNA was isolated and the expression of MMP2 and MMP9 were examined by qPCR. GAPDH was used to serve as a loading control. $(* *, P<0.01, \#, P>0.05) n=3$ 


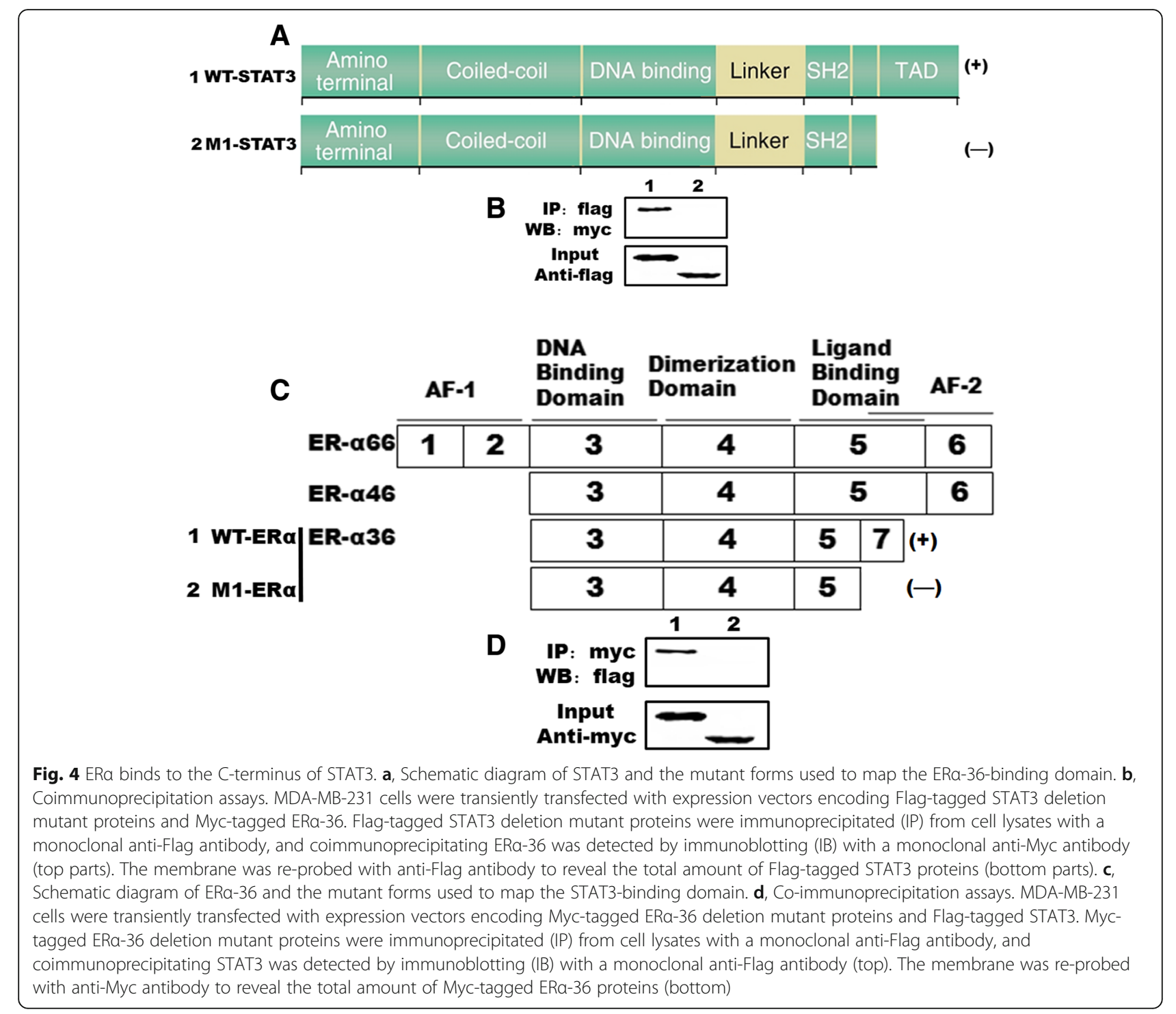

phosphorylation and acetylation, we blocked IL-6-induced STAT3 activation by Ad- dominant-negative STAT3(Ad-dnSTAT3) and tested its effect on STAT3 phosphorylation and acetylation. Blockade of ER $\alpha-36$ activation did inhibit STAT3 phosphorylation and acetylation (Fig. 5c). However, overexpression of Addominant-negative ER $\alpha-36$ (Ad-dnER $\alpha$-36) blocked phosphorylation and acetylation at $1 \mathrm{~h}$ of IL- 6 treatment (Fig. 5d). These observations led to the conclusion that ER $\alpha-36$ mediates both phosphorylation and acetylation of STAT3 at $1 \mathrm{~h}$ upon IL- 6 treatment. To further confirm the results, ER $\alpha-36$ levels were down-regulated by its siRNA, and its effect was tested on IL-6-induced STAT3 phosphorylation and acetylation. Depletion of ER $\alpha$-36 levels also led to a decrease in IL-6-induced phosphorylation and acetylation of both total and ER $\alpha$ 36 associated-STAT3 (Fig. 5e and f). These results indicate that IL-6-induced STAT3 phosphorylation and acetylation at $1 \mathrm{~h}$ of IL- 6 treatment require ER $\alpha-36$ activation.

STAT3 phospholyation is required for IL-6-induced MMP2 and MMP9 expression and breast cancer cell migration To understand the role of STAT3 acetylation on its tyrosine phosphorylation, we used an acetylation null mutant of STAT3, STAT3K685R [38]. Interference of STAT3 acetylation by STAT3K685R blocked both total and ER $\alpha-36$-associated STAT3 phosphorylation (Fig. 6a and b). This finding indicated that STAT3 acetylation is required for tyrosine phosphorylation. To understand the role of acetylation on IL-6-induced MMP2 and MMP9 expression, MDA-MB-231 cells were cotransfected with STAT3K685R (pCDNA3-mSTAT-3) and pGL3-MMP2luc and pGL3-MMP9-luc construct, Cell were then 


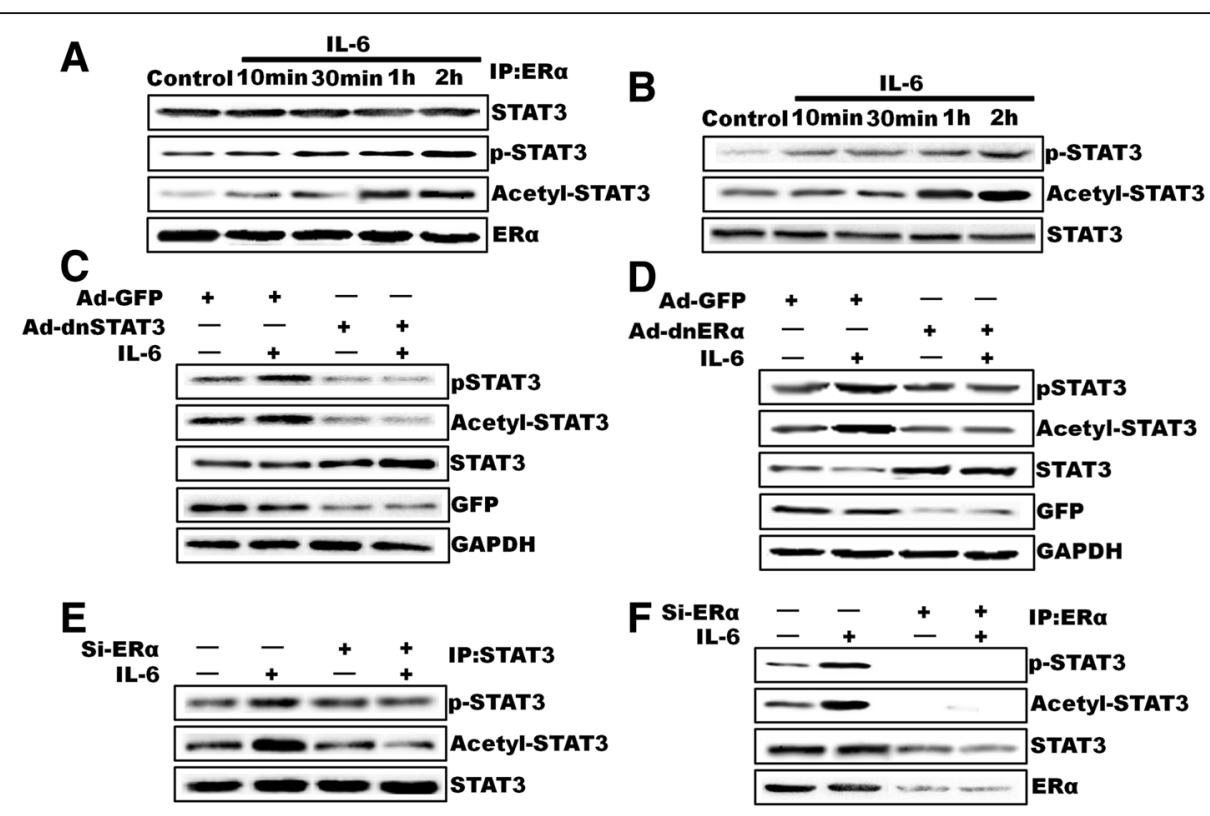

Fig. 5 ERa-36 associates with STAT3 and influences STAT3 phosphoryation and acetylation. a, quiescent MDA-MB-231 cells were treated with and without IL-6 for the indicated time periods, and cell extracts were prepared. An equal amount of protein from control and each treatment was immunoprecipitated (IP) using anti-ERa-36 antibodies, and the immunocomplexes were analyzed by Western blotting for STAT3 using its specific antibodies. The blot was re-probed sequentially with anti-pSTAT3, anti-acetyl-STAT3, and anti-ERa-36 antibodies. b, conditions were same as in A except that an equal amount of protein from control and each treatment was analyzed by Western blotting for STAT3 phosphorylation antibodies. The blot was reprobed sequentially with anti-acetyl-STAT3 and anti-STAT3 antibodies. $\mathbf{c}$ and $\mathbf{d}$, MDA-MB-231 cells that were transduced with Ad-GFP, Ad-dnSTAT3(c) Ad-dnERa-36(d), after $48 \mathrm{~h}$, cells were treated with and without IL-6 for $1 \mathrm{~h}$, and cell extracts were prepared and analyzed by Western blotting using anti-pSTAT3 and/or anti-acetyl-STAT3 antibodies. The blot was re-probed sequentially with antiSTAT3, anti-GFP, and anti-GAPDH antibodies to show the overexpression of dnSTAT3 or dnERa-36 or for normalization. e and f, MDA-MB-231 cells that were transfected with scrambled or ERa-36 siRNA $(100 \mathrm{nM}) .48 \mathrm{~h}$ after transfection, cells were treated with or without IL-6 for $1 \mathrm{~h}$, and cell extracts were prepared. An equal amount of protein from control and each treatment was immunoprecipitated with anti-STAT3 (e) or anti-ERa-36 (f) antibodies, and the immunocomplexes were analyzed by Western blotting using anti-acetyl-STAT3 antibodies. The blot was re-probed sequentially with anti-pSTAT3, anti-STAT3, and/or anti-ERa-36 antibodies

treated with or without IL-6 for $1 \mathrm{~h}$. Cell were then analyzed for MMP2 and MMP9 promoter activity. STAT3K685R mutant reduced IL-6-induced MMP2 and MMP9 promoter-luciferase activity about 2.5 -fold or 2.7-fold, respectively (Fig. $6 \mathrm{c}$ and d). overexpress STAT3K685R also inhibits IL-6-induced breast cancer cell migration about 40\% (Fig. 6 E).

\section{ERa-36 recruits p300 and mediates IL-6-induced STAT3 acetylation}

Previous studies have demonstrated that STAT3 acetylation is mediated by p300 [39]. We propose a hypothesis that ER $\alpha-36$ may recruit p300 and thereby facilitate ER $\alpha$-36-induced STAT3 acetylation. To test this hypothesis, we studied the association of ER $\alpha-36$ and p300 in control versus IL-6-treated MDA-MB-231 by coimmunoprecipitation. As expected, p300 was associated with ER $\alpha-36$ in response to IL-6 (Fig. 7a). Maximum increase in ER $\alpha-36$ and p300 association was detected between 1 and $2 \mathrm{~h}$ of IL- 6 treatment, and this was correlated with the time course of STAT3 acetylation. In addition, blockade of ER $\alpha-36$ activation by TAM (10 M), or Ad-dnER $\alpha$ -
36 resulted in the loss of ER $\alpha-36$ association with p300 (Fig. 7b, c and d). Moreover, knockdown of p300 levels by its siRNA also reduced IL-6-induced total and ER $\alpha$ 36-associated STAT3 acetylation and its late phase phosphorylation (Fig. 7e, $\mathrm{f}$ and $\mathrm{g}$ ). In addition, down-regulation of p300 levels attenuated IL-6- induced MMP2 and MMP9 promoter activity and its expression about 38\% or $40 \%$, respectively (Fig. $7 \mathrm{~h}$ ). These observations strongly support a role of ER $\alpha$-36-recruited p300 in IL6-induced STAT3 acetylation and phosphorylation, leading to MMP2 and MMP9 expression. To understand the functional of p300, we also tested its role in IL-6-induced breast cancer cell migration and proliferation. Down-regulation of p300 levels by its siRNA attenuated IL-6-induced breast cancer cell migration about 60\% (Fig. 7i).

\section{ERa-36 and STAT3 bind to MMP2 and MMP9 promoter and mediate MMP2 and MMP9 expression in response to IL-6}

To identify the critical promoter elements responsible for the effect of STAT3, ER $\alpha$ and their synergy. The 


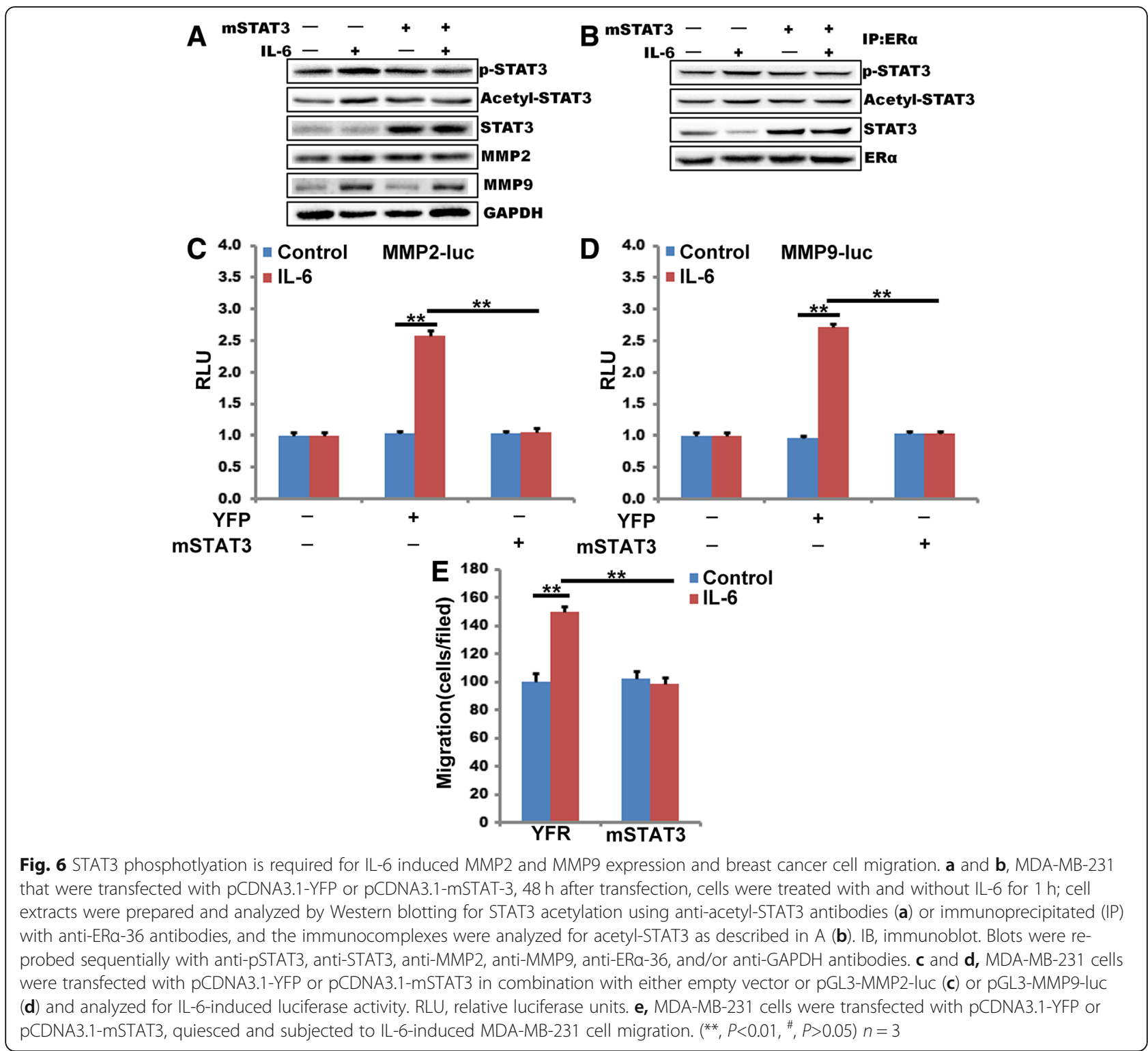

proximal portion of the MMP2 and MMP9 promoter contains several regulatory elements, including one GAS box. To characterize the importance of these elements, we generated a set of luciferase reporter constructs with various mutations of the MMP2 and MMP9 promoter (Fig. 8a and b). Promoter luciferase assay showed both STAT3 and ER $\alpha-36$ induced a modest increase in the promoter activity, whereas the combined treatment acted synergistically (Fig. 8c and d). Interestingly, inactivating mutations of this element alone both inhibited the effect of the individual treatments and affected their synergy. Importantly, Mutation of the GAS had an almost complete inhibitory effect (Fig. 8c and d). Together, these findings indicate that the GAS is necessary and sufficient not only for ER-mediated activation of the promoter but also for the STAT3- triggered response and synergy between these signals.

ChIP assays were used and further confirmed the impact of STAT3 and ER $\alpha-36$ on the MMP2 and MMP9 gene promoters. Our results show that STAT3 binds the GAS of the MMP2 and MMP9 promoter, ER $\alpha-36$ enhances this effect (Fig. 8e and f) and STAT3 bind the GAS of the MMP2 and MMP9 promoter. These results confirmed that GAS is necessary and sufficient for STAT3 and ER $\alpha-36$ mediated MMP2 and MMP9 promoter activity in MDA-MB-231 cells.

MMP2 and MMP9 cellular location in response to IL-6 To test the cellular location of MMP2 and MMP9, we conducted immunofluorescence staining studies to observe the localization of MMP2 and MMP9 during the 

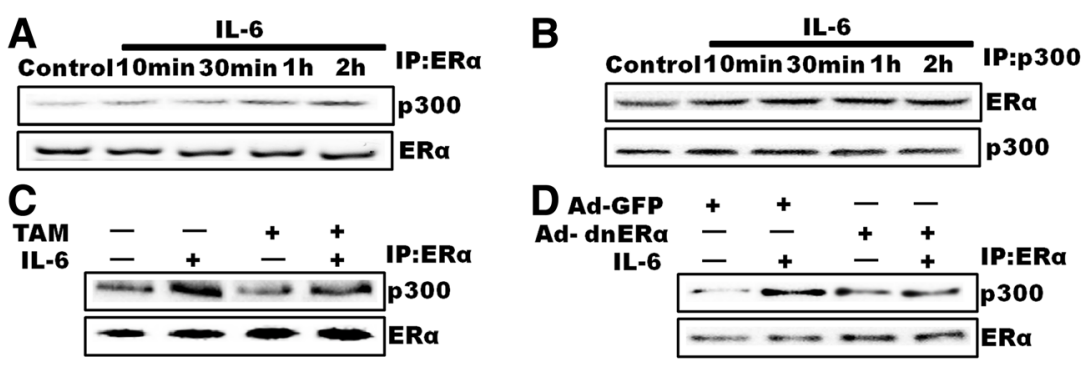

E

$\mathbf{F}$
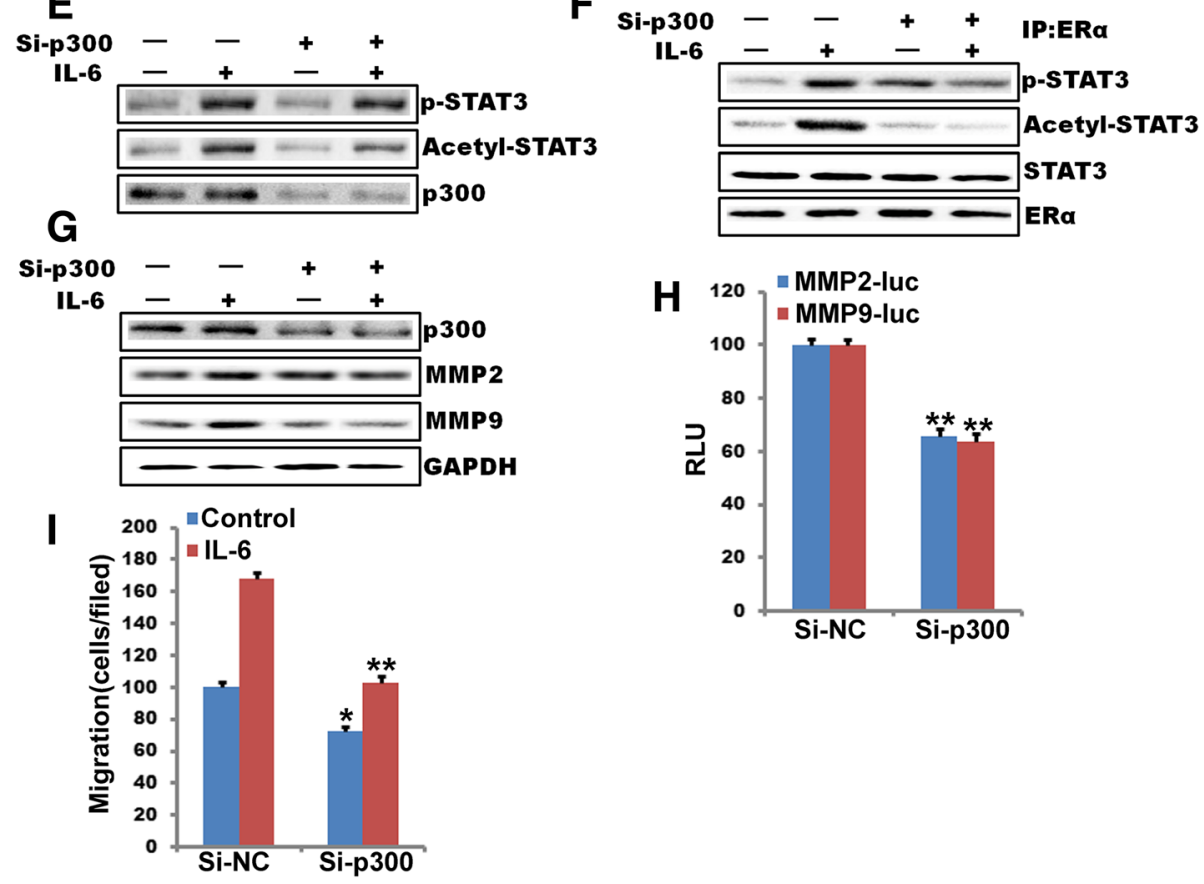

Fig. 7 ERa-36 recruits p300 and mediates IL-6 induced STAT3 acetylation. a and $\mathbf{b}$, quiescent MDA-MB-231 cells were treated with and without IL-6 for the indicated time periods, and cell extracts were prepared. Cell extracts containing an equal amount of protein from control and each treatment were immunoprecipitated (IP) with anti-ERa-36 or anti-p300 antibodies, and the immunocomplexes were analyzed by Western blotting using anti-p300 and/or anti-ERa-36 antibodies. IB, immunoblot. c, quiescent MDA-MB-231 cells were treated with and without IL-6 in the presence and absence of TAM $(10 \mu \mathrm{M})$ for $1 \mathrm{~h}$, and cell extracts were prepared. Cell extracts containing an equal amount of protein from control and each treatment were immunoprecipitated with anti-ERa-36 antibodies, and the immunocomplexes were analyzed by Western blotting using anti-p300 antibodies. $\mathbf{d}$, all the conditions were the same as in B except that MDA-MB-231 cells were transduced with Ad-GFP or Ad-dnERa-36 and quiesced before being treated with IL-6. Using with anti-ERa-36 antibodies to show equal amounts of immunoprecipitated target protein. $\mathbf{e}$, f and $\mathbf{g}$, MDA-MB-231 cells that were transfected with scrambled (Scr) or p300 siRNA (100 nM) and quiesced were treated with and without IL-6 for $1 \mathrm{~h}$, and cell extracts were prepared. Cell extracts containing an equal amount of protein from control and each treatment were analyzed by Western blotting using anti-pSTAT-3 and anti-acetyl-STAT3 antibodies (e) using anti-MMP2 and anti-MMP9 (g) antibodies or subjected to immunoprecipitation using anti-ERa antibodies followed by immunoblotting using anti-acetyl-STAT3 antibodies (f). The blots were reprobed sequentially with anti-pSTAT3, anti-STAT3, and anti-ERa-36 antibodies. h, MDA-MB-231 cells that were transfected with scrambled or p300 siRNA $(100 \mathrm{nM})$ in combination with either empty vector or PGL3-MMP2-luc and PGL3-MMP9-luc, and cell extracts were prepared and analyzed for luciferase activity. RLU, relative luciferase units. i, MDA-MB-231 cells that were transfected with scrambled (Scr) or p300 siRNA (100 nM) and quiesced were treated with and without IL-6 for $1 \mathrm{~h}$ induced MDA-MB-231 cell migration. Bar graphs represent means \pm S.D. values of three independent experiments. $\left.{ }^{* *}, P<0.01,{ }^{*}, P>0.05\right) n=3$

IL-6-induced expression. As seen in Fig. 9a and b, MMP2 and MMP9 were detected in the cytoplasm without IL-6 treatment and translocated to the nucleus treated with IL-6. To further confirm this result, we prepared cytoplasmic and nuclear extracts from IL-6treated MDA-MB-231 cells and analyzed for MMP2 and MMP9 levels in both the fractions. MMP2 and MMP9 were present in the cytoplasmic fraction at without IL-6 treatment. After beening treated with IL-6, MMP2 and MMP9 were detected in both the fractions (Fig. 9c). These results provide further clues supporting our hypothesis that IL- 6 regulates the MMP2 and MMP9 expression, during which it is mostly located in the nuclear and mediate cell migration. 


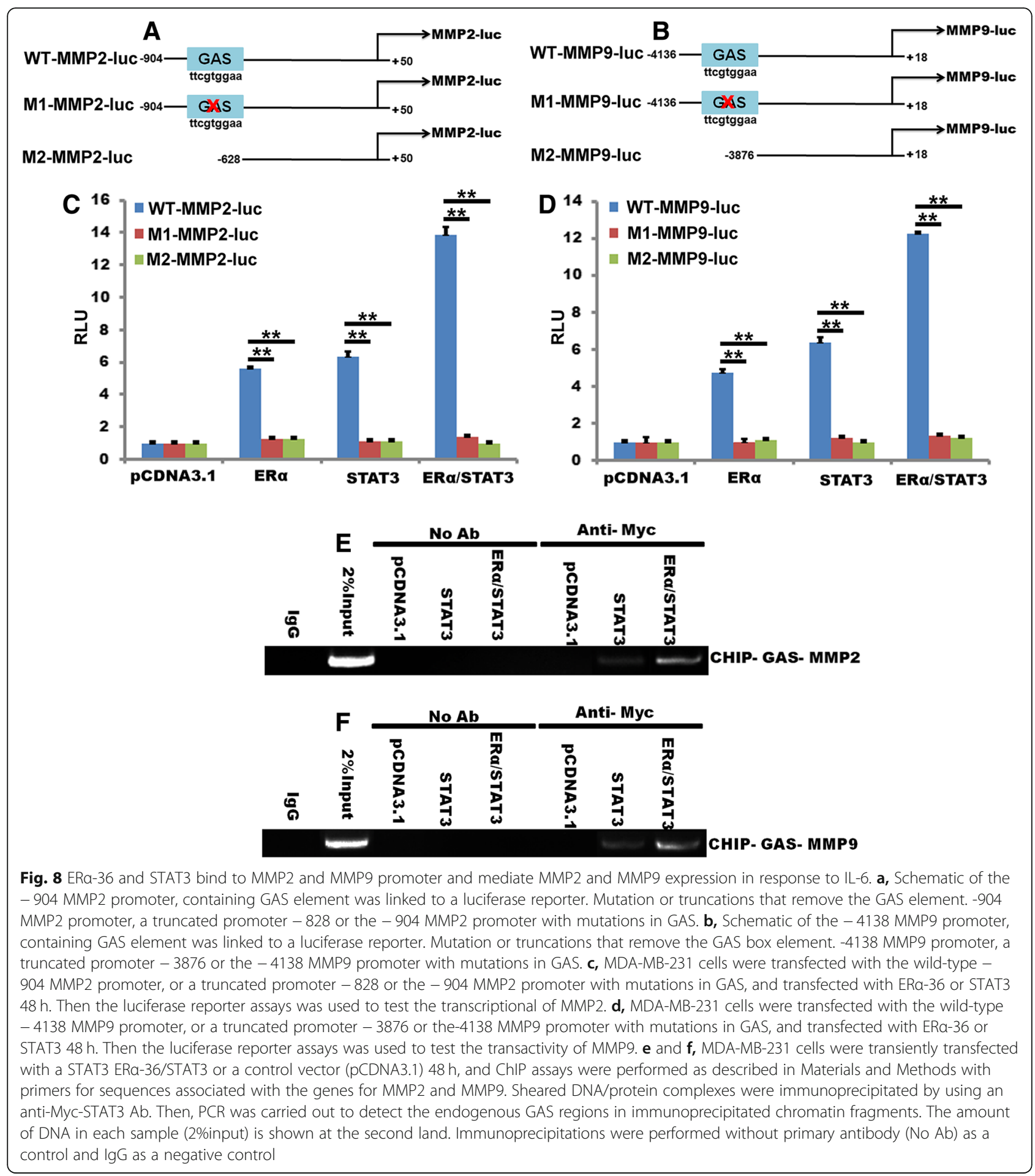

ERa-36 and STAT3 signaling cross-talking human breast cancer cell migration

Since both E2 and IL-6 play crucial roles in mammary gland development, differentiation and tumorigenesis, it would be revealing to see whether the ER-STAT3 crosstalk actually takes place in cells of mammary gland origin. Wound-healing assay data show that the wound treated with ER signal inhibitor TAM, AG490 decreased the rate of wound closure, compare to the control group. More importantly, E2 and IL-6 can synergistically promote the healing of breast cancer cells scratch and migration. (Fig. 10a, b, c and d). Then, three ER expressing human breast cancer cell lines, MDA-MB-231, MCF-7 and MCF10A were used to study such events. Direct 


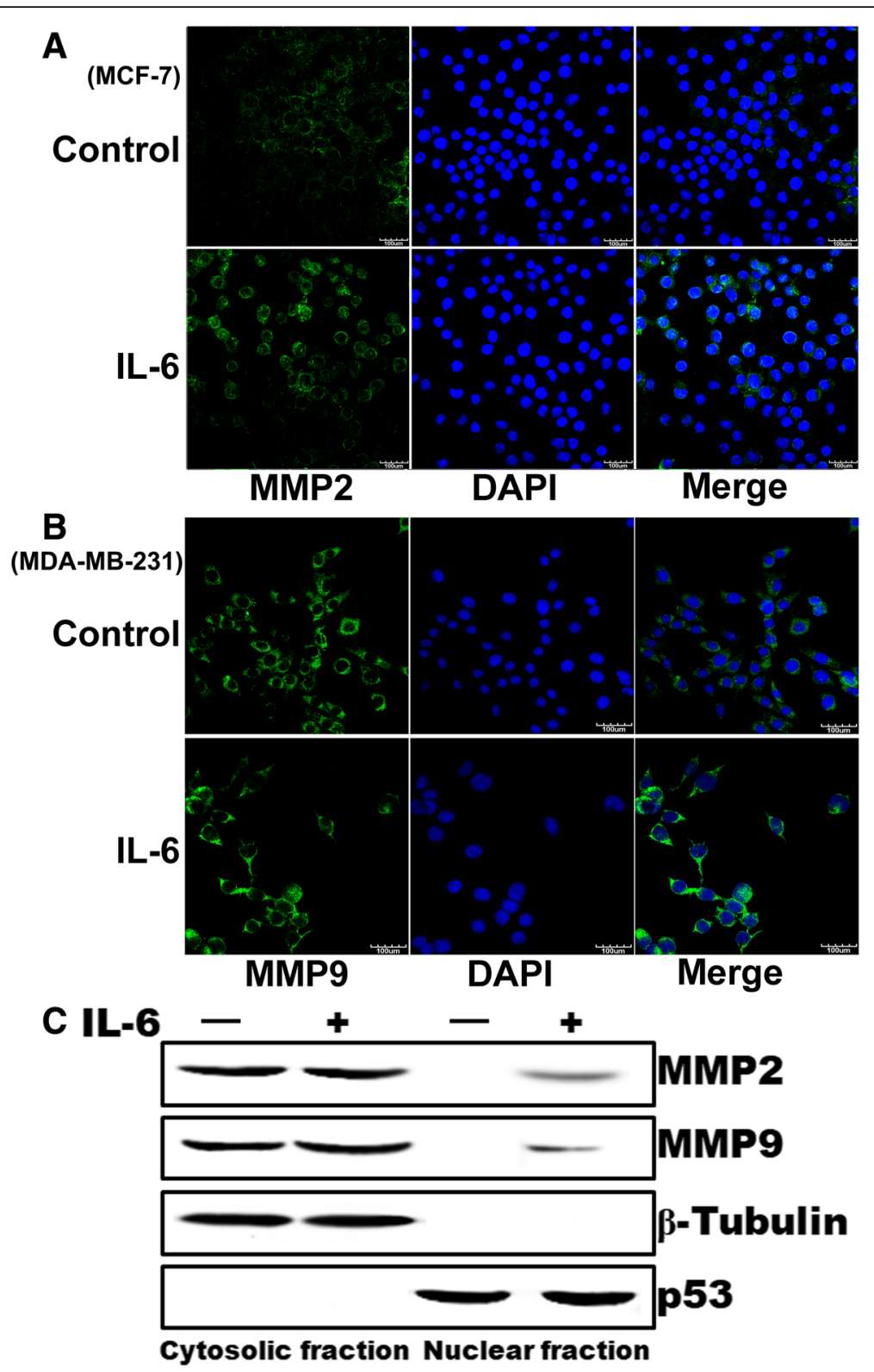

Fig. 9 Translocation of MMP2 and MMP9 the cytoplasm to the nucleus in response to IL-6. $\mathbf{a}$ and $\mathbf{b}$, quiescent MDA-MB-231 cells were treated with and without IL-6 for the indicated time periods, fixed, permeabilized, and immunostained for MMP2 and MMP9 using its specific antibodies followed by probing with Alexa Fluor 488-conjugated secondary antibodies. c, quiescent MDA-MB-231 cells were treated with and without IL-6 for $1 \mathrm{~h}$ and the cytoplasmic and nuclear extracts were prepared. An equal amount of protein from the cytoplasmic and nuclear extracts of control and the IL-6-treated MDA-MB-231 cells was analyzed by Western blotting for MMP2 and MMP9 levels using its specific antibodies. The blot was reprobed sequentially with anti- $\beta$-tubulin and anti-p53 antibodies to show the relative purity of the cytoplasmic and nuclear extracts

association of ER $\alpha-36$ and STAT3 was identified in lysates from both cell lines by co-immunoprecipitation studies (Fig. 10e). For the functional assays, both cells were transfected with the ERE-LUC reporter plasmid and treated with E2 alone, or E2 plus IL-6, to investigate whether addition of IL-6 will influence the ER signaling. Data from this assay indicated that addition of IL-6 induced ER signaling in both cell lines (Fig. 10f). To assess the effect of ER activation on JAK-STAT3 signaling, cells were transfected with the MMP2 and MMP9-luc reporter plasmid and treated with IL-6 alone, or IL- 6 plus E2. The results showed that addition of E2 enhanced IL6 signaling in MDA-MB-231 cells (Fig. 10g).

\section{Discussion}

The pathogenic roles of MMPs in human diseases such as cancer have attracted great attention. The most straightforward explanation for their role in cancer is 


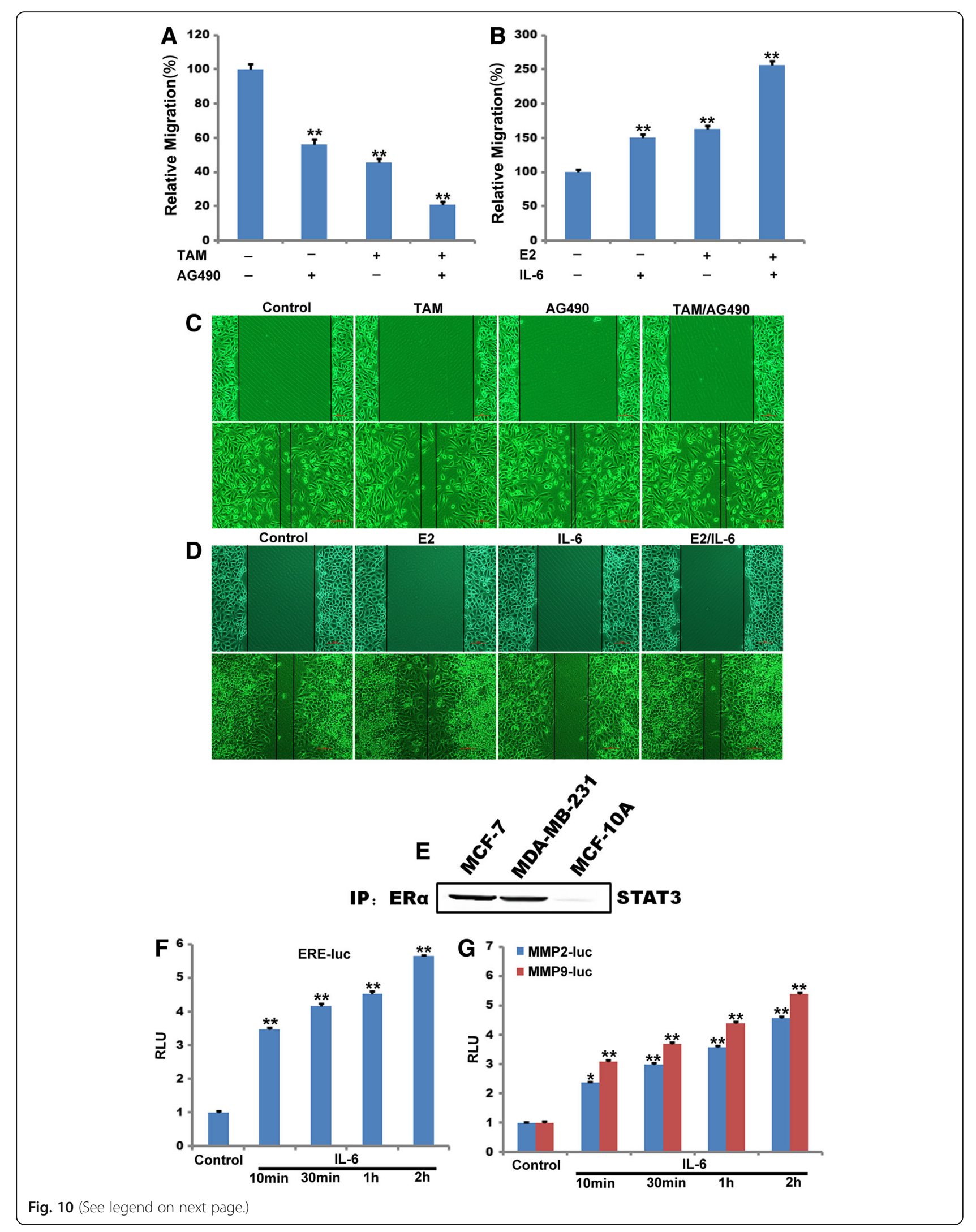


(See figure on previous page.)

Fig. 10 ERa and JAK2-STAT3 signaling cross-talking human breast cancer cell. $\mathbf{a}$ and $\mathbf{b}$, Transwell assay was used to detect the migrationstimulating effects of TAM and AG490 or E2 and IL-6 in MDA-MB-231 cells. The number of cells migrated to the lower side of the transwell chambers was counted and photographed in five fields (the upper, the lower, the left, the right, and the middle) of three independent experiments, and the fold migration was calculated. (The negative control (DMSO) of Fig. 10a and the negative control (DMSO/PBS) of Fig. 10b) $\left({ }^{*} P<0.05,{ }^{*} P<0.01 . n=3\right)$. $\mathbf{c}$ and $\mathbf{d}$, The effect of overexpressed TAM and AG490 or E2 and IL-6 on MDA-MB-231 migration of was detected by Wound-healing assay. E, MDA-MB-231, MCF-7 and MCF-10A cell lysates were immunoprecipitated with an anti-ERa antibody and probed with an anti-STAT3 antibody. $\mathbf{f}$ and $\mathbf{g}$, Effects of IL-6 on ERE transcription activity (f) and effects of IL-6 on MMP2 and MMP9 transcription activity (g) were investigated in MDA-MB-231 cells. The luciferase activity was expressed as a percentage relative to the control was used. All luciferase assays were performed in duplicates. $\left({ }^{*} P<0.05,{ }^{*} P<0.01 . \mathrm{n}=3\right.$ )

that MMPs, through extracellular matrix degradation, pave the way for tumor cell invasion and metastasis [16]. Increasing evidence suggests that high levels of serum IL-6 are associated with poor prognosis, advanced disease, and metastases in breast cancer patients [40, 41]. Our results in this study also showed that IL-6 induced MMP2 and MMP9 expression in breast cancer cell and mediated cell migration.

Previous reports from us and others indicated that STAT3 could promote the proliferation and metastasis of breast cancer cells by EMT pathway [11, 13, 30]. In this study, we found that STAT3 could also mediate IL6-induced MMP2 and MMP9 expression and breast cancer cell migration. Estrogen receptor alpha could mediated proliferation of human breast cancer via a p21/ PCNA/E2F1-dependent pathway [42, 43]. ER $\alpha-36$ is a novel variant of ER- $\alpha$ that have a molecular weight of $36-\mathrm{kDa}$. This $\mathrm{ER} \alpha$ variant differs from the original 66 $\mathrm{kDa} E R \alpha(E R \alpha-66)$, lacking both transcriptional activation domains (AF-1 and AF-2) but retaining the DNAbinding domain and partial dimerization and ligandbinding domains [44]. Our data showed that ER $\alpha-36$ and STAT3 also mediated IL-6-induced MMP2 and MMP9 promoter activity. We also proved that $\mathrm{ER} \alpha-36$ was also associated with STAT3 and influenced phospholyation and acetylation of STAT3, which was required for IL-6induced MMP2 and MMP9 expression and breast cancer cell migration. And Cross-talk between ER $\alpha-36$ and STAT3 was demonstrated to mediate through a direct physical association between the two proteins. By coimmunoprecipitation assays with various constructs of ER $\alpha-36$ and STAT3, it was shown that the C-termini of these two proteins were mainly responsible for this interaction.

STAT3 is also known to be acetylated (Ac) on multiple lysine $(\mathrm{K})$ residues by the $\mathrm{CBP} / \mathrm{p} 300$ histone acetyltransferase in response to cytokines and growth factor signaling. In contrast, recently study showed that insulin stimulated K87 acetylation promote STAT3 mitochondrial translocation and functions [39, 45]. Despite the classical activation of p-STAT3 by JAK2, STAT3 acetylation by $\mathrm{p} 300 / \mathrm{CBP}$ histone acetyltransferase (HAT) is also essential for STAT3 to form stable dimers and to activate STAT3 target gene transcription, acetylated
STAT3 forms stable dimer to translocate into nucleus and binds strongly to the DNA to enhance the transcription of STAT3 target genes $[38,46]$. In this study, we proved that ER $\alpha-36$ recruited p300 and mediated IL-6induced STAT3 acetylation. In additional, ER $\alpha-36$ and STAT3 bind to MMP2 and MMP9 promoter and mediate MMP2 and MMP9 expression in response to IL-6. MMP2 and MMP9 translocated from the cytoplasm to the nuclear in response to IL-6. ER $\alpha-36$ and STAT3cross-talk during human breast cancer cell migration, this provides a novel pathway in breast cancer progression.

\section{Conclusions}

Our studies demonstrate for the first time that the function of MMP2 and MMP9 in breast cancer cell migration, which is mediated by interactions between ER $\alpha-36$ and STAT3.

\section{Abbreviations}

AF-1: Transactivation function; AF-2: Ligand-dependent transactivation; BRMS1: Breast cancer metastasis suppressor 1; DAPI: 4',6-diamidino-2phenylindole; DBD: DNA-binding domain; DMEM: Dulbecco's modified Eagle's medium; EB: Ethidium bromide; EMT: Epithelial to mesenchymal transition; ER: Estrogen receptor; ERE: Estrogen response elements; HAT: Histone acetyltransferase; LBD: Ligand binding domain;

OPN: Osteopontin; UPA: Plasminogen activator

\section{Acknowledgements}

X.H. Liao, L.Y. Bao, and T.C.Zhang were supported by National Natural Science Foundation of China.

\section{Authors' contributions}

X.H.L. and L.Y.B. designed research; X.H.L., X.Y., and J.P.L. performed research; W.G., D.Q.W., A.Y., H.M.Z., F.H., H.H.L, Z.T.D., Z.J.Z., and H.L. analyzed data; and X.H.L., K.C., Y.T., and L.Y.B. wrote the paper. All authors read and approved the final manuscript.

\section{Author's information}

Yuan Xiang, Jia Peng Li, Ao Yao, Hui-Min Zhang, Feng Huang, Han-Han Li, Zhou-Tong Dai, Zi-Jiang Zhang, Hui Li, LeYuan Bao, Xing-Hua Liao are from Institute of Biology and Medicine, Wuhan University of Science and Technology, P.R.China.

Wei Guo and Xing-Hua Liao are from Shenzhen Ritzcon Biological Technology Co., LTD, Shenzhen, Guangdong, P.R.China.

Yao Tan is from The Affiliated Tumor Hospital of Xinjiang Medical University, Urumqi, Xinjiang Uygur Autonomous Region, P.R.China.

Dan-Qun Wang is from Yiling Hospital, Yichang, Hubei Province, P.R.China. Kun Chen is from College of Pharmaceutical, Liaocheng University,

Shandong, China. 


\section{Funding}

This work was financially supported by National Natural Science Foundation of China (No. 31501149, 31770815, 31570764) and Hubei Natural Science Foundation (2017CFB537) and Educational Commission of Hubei (B2017009). Hubei Province Health and Family Planning Scientific Research Project (WJ2017M173) and the Science and Technology Young Training Program of the Wuhan University of Science and Technology (2016xz035, 2017xz027) and the Innovation and Entrepreneurship Fund for Graduate of Wuhan University of Science and Technology (JCX2016024,JCX2017032, JCX2017033).

\section{Availability of data and materials}

The data generated during this study are included in this article and its supplementary information files are available from the corresponding author on reasonable request.

\section{Ethics approval and consent to participate}

Not applicable.

\section{Consent for publication}

All authors have read this manuscript and approved for the submission.

\section{Competing interests}

The authors declare that they have no competing interests.

\section{Author details}

${ }^{1}$ Institute of Biology and Medicine, Wuhan University of Science and Technology, Wuhan, Hubei 430081, China. ${ }^{2}$ Shenzhen Ritzcon Biological Technology Co., LTD, Shenzhen, Guangdong 518000, China. ${ }^{3}$ Yiling Hospital, Yichang, Hubei 443000, China. ${ }^{4}$ The Affiliated Tumor Hospital of Xinjiang Medical University, Uygur Autonomous Region, Urumqi, Xinjiang 830011, China. ${ }^{5}$ College of Pharmaceutical, Liaocheng University, Liaocheng, Shandong 252000, China.

Received: 26 March 2019 Accepted: 1 August 2019 Published online: 13 August 2019

\section{References}

1. Gorski J, Welshons W, Sakai D. Remodeling the estrogen receptor model. Molecular \& Cellular Endocrinology. 1984;36:11-5.

2. Mangelsdorf DJ, Thummel C, Beato M, Herrlich P, Schütz G, Umesono K, Blumberg B, Kastner $P$, Mark M, Chambon $P$. The nuclear receptor superfamily: the second decade. Cell. 2000;83:835-9.

3. Enmark E, Gustafsson JA. Oestrogen receptors - an overview. J Intern Med. 2010;246:133-8.

4. Wang Y, Cheng CH. ERalpha and STAT5a cross-talk: interaction through Cterminal portions of the proteins decreases STAT5a phosphorylation, nuclear translocation and DNA-binding. FEBS Lett. 2004;572:238-44.

5. Wang ZY, Zhang XT, Shen P, Loggie BW, Chang YC, Deuel TF. Identification, cloning, and expression of human estrogen receptor-a36, a novel variant of human estrogen receptor-a66. Biochemical \& Biophysical Research Communications. 2005;336:1023-7.

6. Wang Z, Zhang X, Shen P, Loggie BW, Chang Y, Deuel TF. A variant of estrogen receptor-\{alpha\}, hER-\{alpha\}36: transduction of estrogen- and antiestrogen-dependent membrane-initiated mitogenic signaling. Proc Natl Acad Sci U S A. 2006;103:9063-8.

7. Lin SL, Yan LY, Zhang XT, Yuan J, Li M, Qiao J, Wang ZY, Sun QY: ERalpha36, a variant of ER-alpha, promotes tamoxifen agonist action in endometrial cancer cells via the MAPKJERK and PI3KJAkt pathways. PLoS One 2010, 5:e9013-e9013.

8. Becker S, Groner B, Müller CW. Three-dimensional structure of the Stat3beta homodimer bound to DNA. Nature. 1998:394:145.

9. Levy DE, Jr DJ. Stats: transcriptional control and biological impact. Nat Rev Mol Cell Biol. 2002;3:651

10. Mao X, Ren Z, Parker GN, Sondermann H, Pastorello MA, Wang W, Mcmurray JS, Demeler B Jr, DJ CX. Structural bases of unphosphorylated STAT1 association and receptor binding. Mol Cell. 2005;17:761-71.

11. Liao XH, Wang N, Liu LY, Zheng L, Xing WJ, Zhao DW, Sun XG, Hu P, Dong J, Zhang TC. MRTF-A and STAT3 synergistically promote breast cancer cell migration. Cell Signal. 2014;26:2370-80.
12. Xing WJ, Liao XH, Wang N, Zhao DW, Zheng L, Zheng DL, Dong J, Zhang TC. MRTF-A and STAT3 promote MDA-MB-231 cell migration via hypermethylating BRSM1. IUBMB Life. 2015;67:202-17.

13. Xiang Y, Liao XH, Yu CX, Yao A, Qin H, Li JP, Hu P, Li H, Guo W, Gu CJ. MiR93-5p inhibits the EMT of breast cancer cells via targeting MKL-1 and STAT3. Exp Cell Res. 2017:357.

14. Banerjee $\mathrm{K}$, Resat $\mathrm{H}$. Constitutive activation of STAT3 in breast cancer cells: a review. Int J Cancer. 2016;138:2570-8.

15. Song Y, Qian L, Song S, Chen L, Zhang Y, Yuan G, Zhang H, Xia Q, Hu M, Yu M. Fra-1 and Stat3 synergistically regulate activation of human MMP-9 gene. Mol Immunol. 2008;45:137-43.

16. Kai K, Wang CY, Werb Z. Matrix metalloproteinases in stem cell regulation and cancer. Matrix Biol. 2015:44-46:184-90.

17. Gao Y, Guan Z, Chen J, Xie H, Yang Z, Fan J, Wang X, Li L. CXCL5/CXCR2 axis promotes bladder cancer cell migration and invasion by activating PI3K/AKTinduced upregulation of MMP2/MMP9. Int J Oncol. 2015;47:690-700.

18. Jin J, Cai L, Liu ZM, Zhou XS. miRNA-218 inhibits osteosarcoma cell migration and invasion by down-regulating of TIAM1, MMP2 and MMP9. Asian Pacific Journal of Cancer Prevention Apjcp. 2013;14:3681-4.

19. Dou CY, Cao CJ, Wang Z, Zhang RH, Huang LL, Lian JY, Xie WL, Wang LT. EFEMP1 inhibits migration of hepatocellular carcinoma by regulating MMP2 and MMP9 via ERK1/2 activity. Oncol Rep. 2016;35:3489-95.

20. Kalhori $\mathrm{V}$, Törnquist K. MMP2 and MMP9 participate in S1P-induced invasion of follicular ML-1 thyroid cancer cells. Molecular \& Cellular Endocrinology. 2015:404:113-22.

21. Lai WC, Zhou M, Shankavaram U, Peng G, Wahl LM. Differential regulation of lipopolysaccharide-induced monocyte matrix metalloproteinase (MMP)-1 and MMP-9 by p38 and extracellular signal-regulated kinase 1/2 mitogenactivated protein kinases. J Immunol. 2003;170:6244-9.

22. Westermarck J, Kähäri V. Regulation of matrix metalloproteinase expression in tumor invasion. Faseb Journal Official Publication of the Federation of American Societies for Experimental Biology. 1999:13:781-92.

23. Chung TW, Lee YC, Kim CH. Hepatitis B viral HBx induces matrix metalloproteinase-9 gene expression through activation of ERK and PI-3K AKT pathways: involvement of invasive potential. Faseb Journal Official Publication of the Federation of American Societies for Experimental Biology. 2004;18:1123-5.

24. Cheng JC, Chou CH, Kuo ML, Hsieh CY. Radiation-enhanced hepatocellular carcinoma cell invasion with MMP-9 expression through $\mathrm{PI} 3 \mathrm{~K} \mid[$ sol] $\mid$ Akt|[sol]]|NF-|[kappa]|B signal transduction pathway. Oncogene. 2006;25:7009-18.

25. Sen M, Reifert J, Lauterbach K, Wolf V, Rubin JS, Corr M, Carson DA Regulation of fibronectin and metalloproteinase expression by Wnt signaling in rheumatoid arthritis synoviocytes. Arthritis \& Rheumatology. 2010:46:2867-77.

26. Yang JM, Xu Z, Wu H, Zhu H, Wu X, Hait WN. Overexpression of extracellular matrix metalloproteinase inducer in multidrug resistant cancer cells. Molecular Cancer Research Mcr. 2003;1:420.

27. Sethi T, Rintoul RC, Moore SM, Mackinnon AC, Salter D, Choo C, Chilvers ER, Dransfield I, Donnelly SC, Strieter R. Extracellular matrix proteins protect small cell lung cancer cells againstapoptosis: a mechanism for small cell lung cancer growth and drug resistance in vivo. Nat Med. 1999;5:662-8.

28. Pagemccaw A, Ewald AJ, Werb Z. Matrix metalloproteinases and the regulation of tissue remodelling. Nat Rev Mol Cell Biol. 2007:8:221-33.

29. Xiang Y, Liao XH, Yao A, Qin H, Fan L, Li JP, Hu P, Li H, Guo W, Li JY. MRTFA-miR-206-WDR1 form feedback loop to regulate breast cancer cell migration. Exp Cell Res. 2017;18:17.

30. Liu L, Yang J, Zhu X, Li D, Lv Z, Zhang X. Long noncoding RNA H19 competitively binds miR-17-5p to regulate YES1 expression in thyroid cancer. FEBS J. 2016;283:2326-39.

31. Liao XH, Li YQ, Wang N, Zheng L, Xing WJ, Zhao DW, Yan TB, Wang Y, Liu LY, Sun $X G$. Re-expression and epigenetic modification of maspin induced apoptosis in MCF-7 cells mediated by myocardin. Cell Signal. 2014;26:1335-46.

32. Wang SW, Sun YM. The IL-6/JAK/STAT3 pathway: potential therapeutic strategies in treating colorectal cancer (review). Int J Oncol. 2014;44:1032-40.

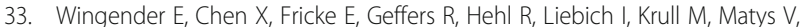
Michael H, Ohnhäuser R. The TRANSFAC system on gene expression regulation. Nucleic Acids Res. 2001;29:281.

34. Wingender $E$, Dietze $P$, Karas $H$, Knüppel R. TRANSFAC: a database on transcription factors and their DNA binding sites. Nucleic Acids Res. 1996;24: 238-41. 
35. Guschin D, Rogers N, Briscoe J, Witthuhn B, Watling D, Horn F, Pellegrini S, Yasukawa K, Heinrich P, Stark GR. A major role for the protein tyrosine kinase JAK1 in the JAK/STAT signal transduction pathway in response to interleukin-6. EMBO J. 1995:14:1421-9.

36. Levy DE, Lee CK. What does Stat3 do? I Clin Investig. 2002;109:1143-8.

37. Wang R, Cherukuri P, Luo J. Activation of Stat3 sequence-specific DNA binding and transcription by p300/CREB-binding protein-mediated acetylation. J Biol Chem. 2005;280:11528-34.

38. Yuan ZL, Guan YJ, Chatterjee D, Chin YE. Stat3 dimerization regulated by reversible acetylation of a single lysine residue. Science. 2005;307:269-73.

39. Avalle L, Camporeale A, Camperi A, Poli V. STAT3 in cancer: a double edged sword. Cytokine. 2017.

40. Yao X, Huang J, Zhong H, Shen N, Faggioni R, Fung M, Yao Y. Targeting interleukin-6 in inflammatory autoimmune diseases and cancers. Pharmacol Ther. 2014;141:125-39.

41. Dethlefsen C, Højfeldt G, Hojman P. The role of intratumoral and systemic IL-6 in breast cancer. Breast Cancer Res Treat. 2013;138:657-64.

42. Xiang Y, Lu DL, Li JP, Yu CX, Zheng DL, Huang X, Wang ZY, Hu P, Liao XH, Zhang TC. Myocardin inhibits estrogen receptor alpha-mediated proliferation of human breast cancer MCF-7 cells via regulating MicroRNA expression. IUBMB Life. 2016;68:477-87.

43. Liao XH, Lu DL, Wang N, Liu LY, Wang Y, Li YQ, Yan TB, Sun XG, Hu P, Zhang TC. Estrogen receptor a mediates proliferation of breast cancer MCF -7 cells via a p21/ PCNA / E 2 F 1 §゙ependent pathway. FEBS J. 2014;281: $927-42$.

44. Liang S, Bin D, Zhongwu L, Yunwei L, Tao O, Jinfeng L, Tianfeng W Zhaoqing F, Tie F, Benyao L. Expression of ER-\{alpha\}36, a novel variant of estrogen receptor $\{a \mid p h a\}$, and resistance to tamoxifen treatment in breast cancer. Journal of Clinical Oncology Official Journal of the American Society of Clinical Oncology. 2009;27:3423.

45. Xu YS, Liang JJ, Wang Y, Zhao XJ, Xu L, Xu YY, Zou QC, Zhang JM, Tu CE, Cui YG. STAT3 undergoes acetylation-dependent mitochondrial translocation to regulate pyruvate metabolism. Sci Rep. 2016;6:39517.

46. Ying W, Zhou C, Hui G, Li C, Dong L, Liu P, Min H, Shen X, Liang L. Therapeutic effect of Cryptotanshinone on experimental rheumatoid arthritis through downregulating p300 mediated-STAT3 acetylation. Biochem Pharmacol. 2017;138:119.

\section{Publisher's Note}

Springer Nature remains neutral with regard to jurisdictional claims in published maps and institutional affiliations.

Ready to submit your research? Choose BMC and benefit from:

- fast, convenient online submission

- thorough peer review by experienced researchers in your field

- rapid publication on acceptance

- support for research data, including large and complex data types

- gold Open Access which fosters wider collaboration and increased citations

- maximum visibility for your research: over $100 \mathrm{M}$ website views per year

At BMC, research is always in progress.

Learn more biomedcentral.com/submissions 